\title{
Predictors of immunodeficiency-related death in a cohort of low-income people living with HIV: a competing risks survival analysis
}

\author{
M. F. P. M. ALBUQUERQUE ${ }^{1}$, D. N. ALVES ${ }^{1}$, C. C. BRESANI SALVI ${ }^{1,2} *$, \\ J. D. L. BATISTA ${ }^{3}$, R. A. A. XIMENES ${ }^{4,5}$, D. B. MIRANDA-FILHO ${ }^{5}$, \\ H. R. L. MELO ${ }^{4}$, M. MARUZA ${ }^{6}$ AND U. R. MONTARROYOS ${ }^{5}$ \\ ${ }^{1}$ Centro de Pesquisas Aggeu Magalhães/Fundação Oswaldo Cruz, Pernambuco, Brazil \\ ${ }^{2}$ Instituto Nacional do Seguro Social, Brasília, Brazil \\ ${ }^{3}$ Universidade Federal da Fronteira Sul, Santa Catarina, Brazil \\ ${ }^{4}$ Universidade Federal de Pernambuco, Brazil \\ ${ }^{5}$ Universidade de Pernambuco, Brazil \\ ${ }^{6}$ Hospital Correia Picanço, Secretaria Estadual de Saúde, Pernambuco, Brazil
}

Received 4 June 2016; Final revision 30 November 2016; Accepted 7 December 2016; first published online 9 January 2017

\section{SUMMARY}

We conducted a survival analysis with competing risks to estimate the mortality rate and predictive factors for immunodeficiency-related death in people living with HIV/AIDS (PLWH) in northeast Brazil. A cohort with 2372 PLWH was enrolled between July 2007 and June 2010 and monitored until 31 December 2012 at two healthcare centres. The event of interest was immunodeficiencyrelated death, which was defined based on the Coding Causes of Death in HIV Protocol (CoDe). The predictor variables were: sociodemographic characteristics, illicit drugs, tobacco, alcohol, nutritional status, antiretroviral therapy, anaemia and CD4 cell count at baseline; and treatment or chemoprophylaxis for tuberculosis (TB) during follow-up. We used Fine \& Gray's model for the survival analyses with competing risks, since we had regarded immunodeficiency-unrelated deaths as a competing event, and we estimated the adjusted sub-distribution hazard ratios (SHRs). In $10012 \cdot 6$ person-years of observation there were $3 \cdot 1$ deaths $/ 100$ person-years $(2 \cdot 3$ immunodeficiency-related and 0.8 immunodeficiency-unrelated). TB (SHR 4.01), anaemia (SHR 3.58), CD4 <200 cells $/ \mathrm{mm}^{3}$ (SHR 3.33) and being unemployed (SHR 1.56) were risk factors for immunodeficiency-related death. This study discloses a 13\% coverage by highly active antiretroviral therapy (HAART) in our state and adds that anaemia at baseline or the incidence of TB may increase the specific risk of dying from HIV-immunodeficiency, regardless of HAART and CD4.

Key words: Cohort studies, HIV, mortality, risk factor.

\section{INTRODUCTION}

Two decades after the introduction of highly active antiretroviral therapy (HAART) [1] with its impact

\footnotetext{
* Author for correspondence: Dr C. C. Bresani Salvi, Departamento de Saúde Coletiva-NESC, Av. Professor Moraes Rego, s/n - Cidade Universitária - CEP 50·740-465 - Recife, Pernambuco, Brasil. (Email: cristiane.bresani@inss.gov.br)
}

on the overall mortality of people living with HIV/ AIDS (PLWH), there has been a decrease in the ratio between deaths related and unrelated to immunodeficiency in several cohorts throughout developed countries [2]. A number of European countries currently present a predominance of deaths caused by nonAIDS-defining infections and cancers, liver disease and drug abuse [3-5]. However, immunodeficiency-related 
conditions remain the leading causes of death in many parts of the world [2], particularly in low-income regions, such as Brazil [6, 7].

In Brazil, HAART has been widely available since 1996. This has resulted in the reduction of infectious and parasitic diseases, and in the consequent increase in the proportion of deaths unrelated to HIV immunodeficiency [6, 7]. Nevertheless, the Brazilian mortality pattern has not changed as expressively as in other countries [2, 7]. In Brazil, HIV/AIDS mortality rates rose by $2 \%$ per year from 2005 to 2015 . Last year there were 33800 new HIV infections and 21000 deaths from HIV/AIDS, along with a 50\% coverage by HAART in the country [8]. Therefore, it is essential that deaths related to HIV immunodeficiency and its predictive factors are correctly identified in order that interventions may be aimed at reducing lethality from this disease.

Studies have detected a strong association between the risk of immunodeficiency-related death and clinical factors, such as low CD4 cell count, low weight, anaemia and tuberculosis (TB) [9-11]. This association has also been verified with lifestyle, such as the use of illicit drugs, tobacco or alcohol [12, 13]. However, the diversity of classification systems used to relate death to HIV immunodeficiency may cause bias in these estimates [14]. In much of the research studies, the definition of death related and unrelated to HIV immunodeficiency is based on the International Classification of Diseases (ICD), but the ICD does not cover the entire spectrum of diseases and conditions related to HIV and its treatments [4, 14]. In addition, estimates on the pattern of mortality in PLWH may be biased by competing risk from other causes of death, which may prevent observation of the causespecific risk of death from immunodeficiency [15].

There are few evidences from South America, among which two studies from the southeast of Brazil used an international standardized protocol for classifying deaths $[6,7]-$ the Coding causes of Death in HIV (CoDe) [4]. One of these studies addressed the bias from the concurrent risk of immunodeficiency-unrelated deaths [6]. Northeast Brazil is poorer than the southeast, presenting different estimates on HIV/AIDS. In the southeast, AIDS diagnosis and mortality rates are decreasing, currently standing at $18 \cdot 6$ and $5 \cdot 7 / 100000$ population, respectively, while in the northeast both rates have increased to levels of $15 \cdot 2$ and $4 \cdot 3 / 100000$ [16].

PLWH in the northeast of Brazil present multiple causes of death with profiles from the HAART and
pre-HAART eras [17], and a very high incidence of TB co-infection (2·8/100 person-years) [18]. Therefore, this study aimed to identify risk factors for immunodeficiency-related death in a cohort of PLWH in this region. We classified the deaths using the CoDe protocol [4], and then we conducted a competing risks survival analysis with the Fine \& Gray model [19], which weights the immunodeficiency-unrelated deaths as a competing event.

\section{METHODS}

This was a cohort study with a survival analysis of an adult population of PLWH attending specialized care services for HIV/AIDS in the state of Pernambuco, in the northeast of Brazil. The study was located in two hospitals from the Brazilian integrated health system (Sistema Único de Saúde; SUS), Hospital Universitário Oswaldo Cruz (HUOC) and Hospital Correia Picanço (HCP), which encompassed $70 \%$ of PLWH in our state at the time of recruitment.

The study was approved by the Ethics Committee of the Universidade Federal de Pernambuco (CEP/ CCS/UFPE 254/05), and all participants underwent the informed consent process prior to being enrolled in the study. This report follows the STROBE checklist.

The study population consisted of outpatients and inpatients at HUOC and HCP, of whom $<5 \%$ refused to participate, resulting in a consecutive sample of 2372 PLWH enrolled from July 2007 to June 2010 and followed until December 2012. The participants were aged $\geqslant 17$ years, and no criteria were established for exclusion or withdrawal from the study.

The outcome was the event of death, classified as immunodeficiency-related or immunodeficiency-unrelated. The monitoring and collection of data regarding mortality were conducted periodically with searches on the Pernambuco Mortality Information System (SIM) database, which thus prevented follow-up losses until the study ended on 31 December 2012. We collected the date of death, and the immediate, intermediate and underlying causes of death (ICD-10 codes) from SIM, using the probabilistic linkage program RecLink III [20]. Following this, causes of death were re-coded in our dataset and classified as immunodeficiencyrelated or immunodeficiency-unrelated, according to the CoDe Protocol [4].

The CoDe Protocol was developed by the Copenhagen HIV Programme-Centre for Health and Infectious Disease Research (CHIP), and is publicly available free of charge on the CHIP homepage 
(www.cphiv.dk/CoDe). The CoDe comprises two processes, the first uses a Case Report Form to collect sociodemographic and clinical data from the death case, and the second is a Review Form consisting of a matched case review to determine the sequence of events that led to death, to codify the causes of death, and to classify them as immunodeficiency-related or -unrelated. In the present study, we only applied the CoDe Review Form, since we had no data to apply to the Case Report Form [4]. Two specialist professionals (C.C.B. and J.D.L.B.) independently classified each case, based on the underlying, intermediate and immediate causes of death recorded by SIM. Discordant cases were defined by another specialist (M.F.P.M.A.).

According to the CoDe Protocol [4], deaths from external causes were considered definitely unrelated to immunodeficiency, while cases with an AIDSdefining condition or Hodgkin's lymphoma as an underlying, intermediate or immediate cause were classified as definitely related to immunodeficiency. The remaining cases were all considered as non-sudden deaths, and thus were classified as either related or unrelated to immunodeficiency, depending on the CD4 cell count of $<200$ or $\geqslant 200$ cells $/ \mathrm{mm}^{3}$, respectively. To this end, we assessed the CD4 cell counts closest to death from the year preceding death. The 103 cases with no information on CD4 cell counts within 365 days before death were classified through consensus by the three reviewers, based only on the causes of death.

The independent variables as predictors of immunodeficiency-related death included sociodemographic (sex, age group, individual monthly income, literacy, work, social support); life habits (alcohol, smoking, illicit drugs) and clinical characteristics at baseline (HAART, CD4 cell count, anaemia, nutritional status) or during the cohort (treatment for TB, chemoprophylaxis for TB).

Age was categorized into age groups $(<40$ or $\geqslant 40$ years) and income as $<1$ or $\geqslant 1$ minimum salary. The mean values of the Brazilian minimum salary were as follows: US\$185.64 (2007); US\$246.88 (2008); US\$198.13 (2009); US\$295.82 (2010); US\$327.92 (2011); US\$332.98 (2012). Social support was considered absent if the patient was homeless or living alone. Alcohol consumption was categorized according to criteria from the Centers for Disease Control and Prevention [21], as non-drinker, light drinker (up to 2 drinks/day for men and 1 drink/day for women) and excessive drinker ( $>2$ drinks/day for men and 1 drink/day for women).
Smoking was classified as: non-smoker, ex-smoker (not smoking at the time of interview nor during the previous 6 months) and current smoker (smoking at the time of the interview or had given up smoking for $<6$ months). Illicit drug use was considered if the individual reported ever having used marijuana, cocaine or crack.

The use of HAART was defined if the patient was using a combination of three different antiretroviral drugs at the beginning of the cohort. The nutritional status was based on the body mass index (BMI), using weight and height measured at baseline, and was categorized as underweight $\left(<18 \cdot 5 \mathrm{~kg} / \mathrm{m}^{2}\right)$, normal $\left(18.5-24.9 \mathrm{~kg} / \mathrm{m}^{2}\right)$ or overweight/obese $\left(\geqslant 25 \mathrm{~kg} / \mathrm{m}^{2}\right)$, according to World Health Organization criteria [22]. The CD4 cell counts at baseline were categorized as $<200$ or $\geqslant 200$ cells $/ \mathrm{mm}^{3}$. The diagnosis of anaemia at baseline was defined if the haemoglobin concentration $(\mathrm{Hb})$ was $<12 \mathrm{~g} / \mathrm{dl}$ for women and $<14 \mathrm{~g} / \mathrm{dl}$ for men, according to EuroSIDA criteria [23]. The CD4 cell count and $\mathrm{Hb}$ at baseline were considered as the first measurements within the first year of follow-up.

The variable 'treatment for tuberculosis' was defined as the treatment prescribed by the attending physician, according to the Brazilian Ministry of Health protocol (assessing clinical findings and/or acid-alcohol-resistant bacillus in sputum and/or culture for Mycobacterium tuberculosis) [24]. Asymptomatic individuals with a positive tuberculin skin test (TST) are recommended for latent tuberculosis infection (LTBI) treatment, based on the Brazilian Ministry of Health protocol, which recommends the use of $300 \mathrm{mg}$ isoniazid for 6 months [24]. The variable 'chemoprophylaxis for tuberculosis' was categorized as: 'not indicated and not treated' (a negative TST), 'indicated and treated' (a positive TST and treated for LTBI), 'indicated and not treated' (a positive TST and not treated for LTBI), 'no tuberculin skin test' [25].

Sociodemographic, lifestyle habits and clinical data were collected at the time of enrolment, from interviews and information from hospital records. Information was also collected periodically during follow-up from these same sources regarding the treatment for TB, results of TST and treatment for LTBI. Weight and height were measured at baseline with calibrated, standardized instruments.

Samples for the CD4 cell count and M. tuberculosis culture were collected in the laboratory of the respective hospitals and sent to the Pernambuco Central Laboratory (Lacen-PE) or the Julião Paulo da Silva Municipal Laboratory (for the CD4 cell counts of HUOC patients). The $\mathrm{Hb}$, sputum smear and TST 
were conducted within the respective services. Results of the $\mathrm{Hb}$ and $\mathrm{CD} 4$ cell counts were obtained from hospital records. All information and results from clinical and laboratory measurements were collected and recorded on a standardized instrument developed specifically for this study.

\section{Processing and analysing data}

Survival analyses were conducted using the statistical method for the sub-distribution of hazards, proposed by Fine \& Gray [19], which estimates the sub-distribution hazard ratios (SHRs), calculating the median of follow-up time until failure by the event of interest, and attributing a weighted risk to other causes of failure (competing event), rather than censoring. According to Pintile [15], the standard survival analysis based on the Kaplan-Meier method always overestimates the true probabilities of the event of interest in a competing risks situation. Indeed, we aimed to estimate the risk of HIV-related death, thus individuals who died from HIV-unrelated causes could not to be observed during the total periods under risk of HIV-related death, increasing the ratio between the number of HIV-related deaths and total follow-up periods in the cohort.

For our analysis, the dependent variable was the time period between entry to the study and immunodeficiency-related death (event of interest); and the competing event was the time until immunodeficiency-unrelated death. All independent variables (sociodemographic, lifestyle, clinical) were analysed as categorical variables. An additional category 'no information' was created for variables with more than 5\% missing data (CD4 and $\mathrm{Hb}$ ).

In the bivariate analysis, we estimated the association between each independent variable and immunodeficiency-related deaths, using the SHR, a confidence interval (CI) of $95 \%$ and the $P$ value. The variables with $P \leqslant 0.25$ in the bivariate analysis were included in the multivariate regression models. We ran a saturated model with all covariates with a $P$ value of at least $0 \cdot 25$ in the bivariate analysis, and a final model, using the backward stepwise selection method, hence the variables with $P<0.05$ were maintained in the final model. Additionally, we performed a sensitivity analysis by repeating the same analytical steps with the subgroup of patients whose CD4 count results were available. Stata v. 12.0 software (StataCorp., USA) was used to perform the analyses.

For this study, there was no previous sample size calculation. The power of the study was calculated a posteriori to detect the differences between the incidence of immunodeficiency-related death in patients who had and who had not CD4 $<200$ cells $/ \mathrm{mm}^{3}$ (90.5\% vs. $49 \cdot 6 \%$ ), anaemia ( $81 \%$ vs. $49 \cdot 4 \%)$ and treatment for TB $(87 \%$ vs. $66 \%)$. Our sample size has a power of at least $94 \%$ (96\% for association with CD4 $<200$ cells $/ \mathrm{mm}^{3}, 94 \%$ for anaemia, and $95 \%$ for treatment for TB).

\section{Ethical standards}

The authors assert that all procedures contributing to this work comply with the ethical standards of the relevant national (National Council of Health, Brazil) and institutional committees (approval by the Ethics Committee of the Centro de Ciências da Sáude/ Universidade Federal de Pernambuco 254/05) on human experimentation and with the Helsinki Declaration of 1975, as revised in 2008 .

\section{RESULTS}

The cohort included 2372 PLWH, who were enrolled between July 2007 and June 2010 and followed until 31 December 2012, resulting in 10012.6 person-years of observation. The mean age of participants was $39 \cdot 3$ years (s.D. $=9 \cdot 7$ ), $62.5 \%$ were male and $72.6 \%$ were using HAART at the beginning of the cohort. The median of income was $\mathrm{R} \$ 380.00\left(\mathrm{Q}_{1}-\mathrm{Q}_{3} 70 \cdot 00\right.$ $511 \cdot 50, n=2328)$. The other continuous variables presented mean values as follow: BMI $23.4 \mathrm{~kg} / \mathrm{m}^{2}$ (s.D. $=4 \cdot 3, n=2309$ ); CD4 at baseline $442 \cdot 4$ cells/ $\mathrm{mm}^{3}$ (s.D. $=294 \cdot 4, n=2076$ ); $\mathrm{Hb}$ at baseline $12 \cdot 5 \mathrm{~g} / \mathrm{dl}$ (s.D. $=1.5, n=833$ ) for women and $13.8 \mathrm{~g} / \mathrm{dl}$ (s.D. $=$ $1 \cdot 9, n=1348$ ) for men. No information was provided on the CD4 cell counts in 16\% of observations, and in $8 \%$ of the $\mathrm{Hb}$ values, during the first year of the cohort. Among the cases of death, 56 (17.8\%) presented only one CD4 count, which functioned as the CD4 at baseline as well as the more recent CD4 count before death.

There were $315(13 \cdot 3 \%)$ deaths from all causes; 232 $(73.6 \%)$ deaths were classified as immunodeficiencyrelated, according to CoDe criteria. AIDS-defining infections were the most common causes of immunodeficiency-related deaths $(30 \%)$, of which TB was the most common $(70 \%)$. The median time from the most recent CD4 cell count until immunodeficiencyrelated death was 192 days $(n=215)$, and until immunodeficiency-unrelated death was 174 days $(n=78)$. It can be observed in Table 1 that some of the studied 
Table 1. Comparison of sociodemographic, life habits and clinical characteristics between immunodeficiency-related and -unrelated deaths in a cohort of 2372 PLWH, 2007-2012

\begin{tabular}{|c|c|c|c|c|}
\hline Variables & $\begin{array}{l}\text { Immunodeficiency- } \\
\text { related deaths } n(\%)\end{array}$ & $\begin{array}{l}\text { Immunodeficiency- } \\
\text { unrelated deaths } n(\%)\end{array}$ & $\begin{array}{l}\text { Survivors } \\
n(\%)\end{array}$ & $P$ value \\
\hline \multicolumn{5}{|l|}{ Baseline characteristics } \\
\hline \multicolumn{4}{|l|}{ Sex } & \multirow[t]{3}{*}{$0 \cdot 013$} \\
\hline Female & $72(31 \cdot 0)$ & $23(27 \cdot 7)$ & $795(38 \cdot 6)$ & \\
\hline Male & $160(69 \cdot 0)$ & $60(72 \cdot 3)$ & $1262(61 \cdot 3)$ & \\
\hline \multicolumn{4}{|l|}{ Age group, years } & \multirow[t]{3}{*}{$0 \cdot 000$} \\
\hline $17-39$ & $140(60 \cdot 3)$ & $27(32 \cdot 5)$ & $1080(52 \cdot 5)$ & \\
\hline$\geqslant 40$ & $92(39 \cdot 7)$ & $56(67 \cdot 5)$ & $977(47 \cdot 5)$ & \\
\hline \multicolumn{4}{|l|}{ Social support } & \multirow[t]{3}{*}{0.623} \\
\hline Lives with family or partner & $188(81 \cdot 0)$ & $64(77 \cdot 1)$ & $1667(81 \cdot 4)$ & \\
\hline Lives alone. in a shelter or on the streets & $44(19 \cdot 0)$ & $19(22 \cdot 9)$ & $382(18 \cdot 6)$ & \\
\hline \multicolumn{4}{|l|}{ Literacy } & \multirow[t]{3}{*}{$0 \cdot 014$} \\
\hline Yes & $190(82 \cdot 6)$ & $72(86 \cdot 7)$ & $1822(89 \cdot 0)$ & \\
\hline No & $40(17 \cdot 4)$ & $11(13 \cdot 3)$ & $244(10 \cdot 9)$ & \\
\hline \multicolumn{4}{|l|}{ In work } & \multirow{3}{*}{$0 \cdot 000$} \\
\hline Yes & $29(12 \cdot 9)$ & $17(20 \cdot 7)$ & $526(25 \cdot 9)$ & \\
\hline No & $196(87 \cdot 1)$ & $65(79 \cdot 3)$ & $1507(74 \cdot 1)$ & \\
\hline \multicolumn{4}{|l|}{ Monthly individual income } & \multirow[t]{3}{*}{$0 \cdot 058$} \\
\hline$\geqslant 1$ minimum salary & $104(45 \cdot 6)$ & $44(54 \cdot 3)$ & $1088(53 \cdot 9)$ & \\
\hline$<1$ minimum salary & $124(54 \cdot 4)$ & $37(45 \cdot 7)$ & $931(46 \cdot 1)$ & \\
\hline \multicolumn{4}{|l|}{ Alcohol } & \multirow[t]{4}{*}{$0 \cdot 001$} \\
\hline Non-drinker & $174(75 \cdot 3)$ & $54(65 \cdot 8)$ & $1276(62 \cdot 3)$ & \\
\hline Light drinker & $37(16 \cdot 0)$ & $16(19 \cdot 5)$ & $554(27 \cdot 1)$ & \\
\hline Excessive drinker & $20(8 \cdot 7)$ & $12(14 \cdot 6)$ & $217(10 \cdot 6)$ & \\
\hline \multicolumn{4}{|l|}{ Smoking } & \multirow[t]{4}{*}{$0 \cdot 011$} \\
\hline Non-smoker & $89(38 \cdot 5)$ & $37(44 \cdot 6)$ & $933(45 \cdot 5)$ & \\
\hline Current smoker & $93(40 \cdot 3)$ & $26(31 \cdot 3)$ & $591(28 \cdot 8$ & \\
\hline Ex-smoker for $\geqslant 6$ months & $49(21 \cdot 2)$ & $20(24 \cdot 1)$ & $528(25 \cdot 7)$ & \\
\hline \multicolumn{4}{|l|}{ Illicit drugs } & \multirow{3}{*}{0.063} \\
\hline Never used & $153(66 \cdot 2)$ & $56(67 \cdot 5)$ & $1495(72 \cdot 9)$ & \\
\hline Used at some point & $78(33 \cdot 8)$ & $27(32 \cdot 5)$ & $555(27 \cdot 1)$ & \\
\hline Using HAART & & & & $0 \cdot 718$ \\
\hline Yes & $32(13 \cdot 8)$ & $11(13 \cdot 2)$ & $248(12 \cdot 1)$ & \\
\hline No & $200(86 \cdot 2)$ & $72(86 \cdot 7)$ & $1809(87 \cdot 9)$ & \\
\hline CD4 cell count & & & & $0 \cdot 000$ \\
\hline$\geqslant 200$ cells $/ \mathrm{mm}^{3}$ & $58(25 \cdot 0)$ & $59(71 \cdot 1)$ & $1471(71 \cdot 5)$ & \\
\hline $1-199 \mathrm{cells} / \mathrm{mm}^{3}$ & $86(37 \cdot 1)$ & $9(10 \cdot 8)$ & $314(15 \cdot 3)$ & \\
\hline Not informed & $88(37 \cdot 9)$ & $15(18 \cdot 1)$ & $272(13 \cdot 2)$ & \\
\hline Anaemia & & & & $0 \cdot 000$ \\
\hline No & $39(16 \cdot 8)$ & $40(48 \cdot 2)$ & $1250(60 \cdot 8)$ & \\
\hline Yes & $143(61 \cdot 6)$ & $34(41 \cdot 0)$ & $675(32 \cdot 8)$ & \\
\hline Not informed & $50(21 \cdot 5)$ & $9(10 \cdot 8)$ & $132(6 \cdot 4)$ & \\
\hline Nutritional status & & & & $0 \cdot 000$ \\
\hline Normal & $137(59 \cdot 0)$ & $45(54 \cdot 2)$ & $1193(59 \cdot 1)$ & \\
\hline Underweight & $43(18 \cdot 5)$ & $8(9 \cdot 6)$ & $171(8 \cdot 5)$ & \\
\hline Overweight/obese & $29(12 \cdot 5)$ & $30(36 \cdot 1)$ & $653(32 \cdot 4)$ & \\
\hline Characteristics during the cohort & & & & \\
\hline Treatment for tuberculosis & & & & $0 \cdot 000$ \\
\hline No & $132(56 \cdot 9)$ & $68(81 \cdot 9)$ & $1887(91 \cdot 7)$ & \\
\hline Yes & $100(43 \cdot 1)$ & $15(18 \cdot 1)$ & $170(8 \cdot 3)$ & \\
\hline Chemoprophylaxis for tuberculosis & & & & $0 \cdot 000$ \\
\hline Not indicated and not treated for LTBI & $57(24 \cdot 6)$ & $28(33 \cdot 7)$ & $741(36 \cdot 0)$ & \\
\hline Indicated and treated for LTBI & $5(2 \cdot 2)$ & $4(4 \cdot 8)$ & $139(6 \cdot 8)$ & \\
\hline Indicated and not treated for LTBI & $11(4 \cdot 7)$ & $2(2 \cdot 4)$ & $126(6 \cdot 1)$ & \\
\hline No tuberculin skin test & $159(68 \cdot 5)$ & $49(59 \cdot 0)$ & $1051(51 \cdot 1)$ & \\
\hline
\end{tabular}

PLWH, People living with HIV/AIDS; HAART, highly active antiretroviral therapy; LTBI, latent tuberculosis infection. Mean values in dollars for Brazilian minimum salary: US\$185.64 (2007); US\$246.88 (2008); US\$198.13 (2009); US\$295.82 (2010); US\$327.92 (2011); US\$332.98 (2012). 
characteristics presented significantly different frequencies between groups of survivors, immunodeficiency-related and -unrelated deaths.

The overall mortality rate in the cohort was $3 \cdot 1 / 100$ person-years, comprising $2 \cdot 3 / 100$ person-years for immunodeficiency-related deaths and $0 \cdot 8 / 100$ personyears for immunodeficiency-unrelated deaths. Patients who died from conditions unrelated to immunodeficiency had a longer contribution of time-at-risk than those who died from immunodeficiency: the mean of 859.6 vs. 626.7 person-years $(P=0.0003)$, respectively. The incidence rate of immunodeficiency-related death per year of entry to the cohort is presented in Table 2, showing a rising trend until 2009, followed by a fall in 2010 .

In the bivariate survival analysis with competing risks (Table 3), only the variables 'social support' and 'HAART' did not obtain a $P$ value $<0 \cdot 25$. Table 4 presents two multivariate models, of which there is a saturated model with all the other variables, and a final model with the selected variables. After applying the backward stepwise method, the variables 'age group', 'sex', 'literacy', 'income', 'smoking' and 'illicit drug' were excluded from the final model. The adjusted SHRs indicated the following risk factors for immunodeficiency-related death (in descending order of their SHR): treatment for TB during cohort, anaemia or a CD4 count $<200$ cells $/ \mathrm{mm}^{3}$ in the first year of the cohort, and being unemployed at baseline.

Table 5 presents a sensitivity analysis by replicating the same bivariate and multivariate analyses considering only the subsample of patients with available CD4 counts. In this subsample $(n=373)$, the variables maintained in the final multivariate model were: treatment for TB during cohort, BMI, anaemia and CD4.

\section{DISCUSSION}

Our estimates on PLWH in the northeast of Brazil demonstrated that deaths attributed to immunodeficiency occurred at a rate of $2 \cdot 3$ deaths $/ 100$ people per year between 2007 and 2012. Immunodeficiency-related deaths were more frequent than immunodeficiencyunrelated deaths with a ratio of almost 3:1. Most of the patients who died from immunodeficiency were not taking HAART at inclusion in the study, although most of them presented a CD4 cell count $<200$ cells/ $\mathrm{mm}^{3}$. Considering immunodeficiency-unrelated deaths as competing events, the adjusted hazard for immunodeficiency-related death was $1 \frac{1}{2}$ times higher in patients who were unemployed; $3 \frac{1}{2}$ times higher in those who presented a CD4 count $<200$ cells $/ \mathrm{mm}^{3}$ or anaemia at
Table 2. Incidence rate of immunodeficiency-related death per year of entrance in a cohort of 2372 PLWH, 2007-2012

\begin{tabular}{lll}
\hline \hline & $\mathrm{N}$ & Mortality rate \\
\hline 2007 & 66 & $1 \cdot 64 / 100$ person-years \\
2008 & 111 & $2 \cdot 3 / 100$ person-years \\
2009 & 47 & $5 \cdot 5 / 100$ person-years \\
2010 & 8 & $4 \cdot 0 / 100$ person-years \\
\hline \hline
\end{tabular}

PLWH, People living with HIV/AIDS.

baseline; and four times higher in patients who received treatment for TB during the cohort.

Immunodeficiency is still a major cause of death of PLWH in some developed countries [2, 26], such as Spain, where $53 \%$ of deaths were related to immunodeficiency in a recent cohort [14]. However, several European regions have reported deaths from other causes as being the most common $[3-5,27]$. In a Swiss cohort, $84 \%$ of deaths between 2005 and 2009 were immunodeficiency unrelated at a rate of $0 \cdot 8 / 100$ person-years, while immunodeficiency-related deaths at $0 \cdot 14 / 100$ person-years occurred [5]. Survival estimates may be discordant in different epidemiological and socioeconomic contexts. In the southeast of Brazil, $49 \%$ of deaths in PLWH were attributed to immunodeficiency between 2005 and 2007 (1-24/100 person-years) [6], and 62\%, between 2007 and 2009 (1·35/100 person-years) [7]. Our study was conducted in a low-income region of the country and encountered even higher estimates which were in accordance with a very high proportion of patients not taking HAART $(86 \%)$.

The high frequencies of low CD4 cell counts and anaemia, and co-infection with TB in patients who died due to HIV immunodeficiency may largely explain the excessive mortality rate, as they were the strongest predictors of immunodeficiency-related death, regardless of HAART at study inclusion. In a cohort of PLWH in the southeast of Brazil it was observed that a low CD4 cell count [hazard ratio (HR) 5.96] and AIDS diagnosis at the baseline (HR $8 \cdot 25)$ significantly increased the risk of death related to immunodeficiency [7]. However, the effects of TB and anaemia were not investigated [7]. Levels of CD4 cells reflects the susceptibility to opportunistic diseases in PLWH [28], of which TB is the leading cause of death [26, 29]. In the HIV/TB co-infection, the viral load increases while the CD4 cell count diminishes [30] and both infections progress [31, 32]. 
Table 3. Bivariate model of sub-distribution hazards from sociodemographic and life habit variables for immunodeficiency-related death, considering other deaths as competing event in 2372 PLWH, 2007-2012

\begin{tabular}{|c|c|c|c|}
\hline Variables & SHR & $(95 \% \mathrm{CI})$ & $P$ value \\
\hline \multicolumn{4}{|l|}{ Sociodemographic and life habits variables } \\
\hline \multicolumn{4}{|l|}{ Sex } \\
\hline Female & $1 \cdot 00$ & & \\
\hline Male & $1 \cdot 35$ & $(1 \cdot 02-1 \cdot 78)$ & $0 \cdot 035$ \\
\hline \multicolumn{4}{|l|}{ Age group, years } \\
\hline $17-39$ & $1 \cdot 00$ & & \\
\hline$\geqslant 40$ & $0 \cdot 71$ & $(0 \cdot 55-0 \cdot 93)$ & $0 \cdot 011$ \\
\hline \multicolumn{4}{|l|}{ Social support } \\
\hline Lives with family or partner & $1 \cdot 00$ & & \\
\hline Lives alone, in a shelter or on the streets & $1 \cdot 05$ & $(0 \cdot 72-1 \cdot 40)$ & $0 \cdot 974$ \\
\hline \multicolumn{4}{|l|}{ Literacy } \\
\hline Yes & $1 \cdot 00$ & & \\
\hline No & $1 \cdot 65$ & $(1 \cdot 18-2 \cdot 33)$ & $0 \cdot 004$ \\
\hline \multicolumn{4}{|l|}{ Monthly individual income } \\
\hline$\geqslant 1$ Minimum salary & $1 \cdot 00$ & & \\
\hline$<1$ Minimum salary & $1 \cdot 40$ & $(1 \cdot 08-1 \cdot 82)$ & $0 \cdot 011$ \\
\hline \multicolumn{4}{|l|}{ Smoking } \\
\hline Never smoked & $1 \cdot 00$ & & \\
\hline Current smoker & $1 \cdot 60$ & $(1 \cdot 19-2 \cdot 13)$ & $0 \cdot 002$ \\
\hline Ex-smoker for $\geqslant 6$ months & $0 \cdot 97$ & $(0 \cdot 68-1 \cdot 37)$ & $0 \cdot 860$ \\
\hline \multicolumn{4}{|l|}{ Illicit drugs } \\
\hline Never used & $1 \cdot 00$ & & \\
\hline Used at some point & $1 \cdot 32$ & $(1 \cdot 01-1 \cdot 73)$ & $0 \cdot 044$ \\
\hline \multicolumn{4}{|l|}{ Alcohol } \\
\hline Non-drinker & $1 \cdot 00$ & & \\
\hline Light drinker & $0 \cdot 50$ & $(0 \cdot 35-0 \cdot 71)$ & $0 \cdot 000$ \\
\hline Excessive drinker & $0 \cdot 65$ & $(0 \cdot 41-1 \cdot 02)$ & $0 \cdot 060$ \\
\hline \multicolumn{4}{|l|}{ In work } \\
\hline Yes & $1 \cdot 00$ & & \\
\hline No & $2 \cdot 31$ & $(1 \cdot 57-3 \cdot 40)$ & $0 \cdot 000$ \\
\hline \multicolumn{4}{|l|}{ Clinical variables } \\
\hline \multicolumn{4}{|l|}{ Using HAART at baseline } \\
\hline$<1$ year & $1 \cdot 00$ & & \\
\hline$\geqslant 1$ year & $0 \cdot 82$ & $(0 \cdot 56-1 \cdot 19)$ & $0 \cdot 299$ \\
\hline \multicolumn{4}{|l|}{ CD4 cell count at baseline } \\
\hline$\geqslant 200$ cells $/ \mathrm{mm}^{3}$ & $1 \cdot 00$ & & \\
\hline $1-199$ cells $/ \mathrm{mm}^{3}$ & $6 \cdot 55$ & $(4 \cdot 72-9 \cdot 10)$ & $0 \cdot 000$ \\
\hline Not informed & $7 \cdot 78$ & $(5 \cdot 59-10 \cdot 82)$ & $0 \cdot 000$ \\
\hline \multicolumn{4}{|l|}{ Anaemia at baseline } \\
\hline No & $1 \cdot 00$ & & \\
\hline Yes & $6 \cdot 27$ & $(4 \cdot 41-8 \cdot 90)$ & $0 \cdot 000$ \\
\hline Not informed & $11 \cdot 74$ & $(7 \cdot 70-17 \cdot 92)$ & $0 \cdot 000$ \\
\hline \multicolumn{4}{|l|}{ Nutritional status at baseline } \\
\hline Normal (eutrophic) & $1 \cdot 00$ & & \\
\hline Underweight & $2 \cdot 14$ & $(1 \cdot 52-3 \cdot 03)$ & $0 \cdot 000$ \\
\hline Overweight & $0 \cdot 40$ & $(0 \cdot 26-0 \cdot 58)$ & $0 \cdot 000$ \\
\hline \multicolumn{4}{|l|}{ Treatment for tuberculosis during the cohort } \\
\hline No & $1 \cdot 00$ & & \\
\hline Yes & $6 \cdot 41$ & $(4 \cdot 95-8 \cdot 30)$ & $0 \cdot 000$ \\
\hline \multicolumn{4}{|c|}{ Chemoprophylaxis for tuberculosis during the cohort } \\
\hline Not indicated and not treated for LTBI & $1 \cdot 00$ & & \\
\hline Indicated and treated for LTBI & $0 \cdot 47$ & $(0 \cdot 19-1 \cdot 18)$ & $0 \cdot 109$ \\
\hline Indicated and not treated for LTBI & $1 \cdot 14$ & $(0 \cdot 60-2 \cdot 15)$ & 0.683 \\
\hline No tuberculin skin test & $1 \cdot 94$ & $(1 \cdot 44-2 \cdot 62)$ & $0 \cdot 000$ \\
\hline
\end{tabular}

PLWH, People living with HIV/AIDS; SHR, sub-distribution hazard ratio; CI, confidence interval; HAART, highly active antiretroviral therapy; LTBI, latent tuberculosis infection.

Mean values in dollars for Brazilian minimum salary: US\$185.64 (2007); US\$246.88 (2008); US\$198.13 (2009); US\$295.82 (2010); US\$327.92 (2011); US\$332.98 (2012). 
Table 4. Multivariate regression models of the sub-distribution hazards of immunodeficiency-related death, considering other deaths as competing event in 2372 PLWH, 2007-2012

\begin{tabular}{|c|c|c|c|c|c|c|}
\hline \multirow[b]{2}{*}{ Variables } & \multicolumn{3}{|c|}{$\begin{array}{l}\text { Saturated multivariate model } \\
(n=2372)\end{array}$} & \multicolumn{3}{|c|}{$\begin{array}{l}\text { Final multivariate model } \\
(n=2372)\end{array}$} \\
\hline & SHR & $(95 \% \mathrm{CI})$ & $P$ value & SHR & $(95 \% \mathrm{CI})$ & $P$ value \\
\hline \multicolumn{7}{|l|}{ Sociodemographic and life habits variables } \\
\hline \multicolumn{7}{|l|}{ Sex } \\
\hline Female & $1 \cdot 00$ & & & & & \\
\hline Male & 0.91 & $(0 \cdot 67-1 \cdot 24)$ & $0 \cdot 567$ & & & \\
\hline \multicolumn{7}{|l|}{ Age group, years } \\
\hline $17-39$ & $1 \cdot 00$ & & & & & \\
\hline$\geqslant 40$ & $0 \cdot 88$ & $(0 \cdot 66-1 \cdot 18)$ & $0 \cdot 400$ & & & \\
\hline \multicolumn{7}{|l|}{ Literacy } \\
\hline Yes & $1 \cdot 00$ & & & & & \\
\hline No & $1 \cdot 27$ & $(0 \cdot 88-1 \cdot 82)$ & $0 \cdot 205$ & & & \\
\hline \multicolumn{7}{|l|}{ Monthly individual income } \\
\hline$\geqslant 1$ Minimum salary & $1 \cdot 00$ & & & & & \\
\hline$<1$ Minimum salary & $0 \cdot 81$ & $(0 \cdot 61-1 \cdot 08)$ & $0 \cdot 161$ & & & \\
\hline \multicolumn{7}{|l|}{ Smoking } \\
\hline Never smoked & $1 \cdot 00$ & & & & & \\
\hline Current smoker & $1 \cdot 40$ & $(1 \cdot 00-1 \cdot 96)$ & $0 \cdot 051$ & & & \\
\hline Ex-smoker for $\geqslant 6$ months & 0.99 & $(0 \cdot 69-1 \cdot 42)$ & $0 \cdot 948$ & & & \\
\hline \multicolumn{7}{|l|}{ Illicit drugs } \\
\hline Never used & $1 \cdot 00$ & & & & & \\
\hline Used at some point & $1 \cdot 13$ & $(0 \cdot 83-1 \cdot 52)$ & $0 \cdot 437$ & & & \\
\hline \multicolumn{7}{|l|}{ Alcohol } \\
\hline Non-drinker & $1 \cdot 00$ & & & $1 \cdot 00$ & & \\
\hline Light drinker & $0 \cdot 60$ & $(0 \cdot 41-0 \cdot 90)$ & $0 \cdot 012$ & $0 \cdot 66$ & $(0 \cdot 45-0 \cdot 98)$ & $0 \cdot 038$ \\
\hline Excessive drinker & $0 \cdot 58$ & $(0 \cdot 37-0 \cdot 90)$ & $0 \cdot 016$ & 0.68 & $(0 \cdot 45-1 \cdot 05)$ & $0 \cdot 080$ \\
\hline \multicolumn{7}{|l|}{ In work } \\
\hline Yes & $1 \cdot 00$ & & & $1 \cdot 00$ & & \\
\hline No & $1 \cdot 47$ & $(0 \cdot 99-2 \cdot 19)$ & $0 \cdot 056$ & $1 \cdot 56$ & $(1 \cdot 05-2 \cdot 32)$ & $0 \cdot 027$ \\
\hline \multicolumn{7}{|l|}{ Clinical variables } \\
\hline \multicolumn{7}{|l|}{ CD4 cell count at baseline } \\
\hline$\geqslant 200$ cells $/ \mathrm{mm}^{3}$ & $1 \cdot 00$ & & & $1 \cdot 00$ & & \\
\hline $1-199$ cells $/ \mathrm{mm}^{3}$ & $3 \cdot 52$ & $(2 \cdot 45-5 \cdot 07)$ & $0 \cdot 000$ & $3 \cdot 33$ & $(2 \cdot 35-4 \cdot 74)$ & $0 \cdot 000$ \\
\hline Not informed & $4 \cdot 63$ & $(3 \cdot 26-6 \cdot 58)$ & $0 \cdot 000$ & $4 \cdot 63$ & $(3 \cdot 31-6 \cdot 48)$ & $0 \cdot 000$ \\
\hline \multicolumn{7}{|l|}{ Anaemia at baseline } \\
\hline No & $1 \cdot 00$ & & & $1 \cdot 00$ & & \\
\hline Yes & $3 \cdot 62$ & $(2 \cdot 51-5 \cdot 23)$ & $0 \cdot 000$ & $3 \cdot 58$ & $(2 \cdot 49-5 \cdot 14)$ & $0 \cdot 000$ \\
\hline Not informed & $5 \cdot 75$ & $(3 \cdot 69-8 \cdot 97)$ & $0 \cdot 000$ & $5 \cdot 93$ & $(3 \cdot 85-9 \cdot 14)$ & $0 \cdot 000$ \\
\hline \multicolumn{7}{|l|}{ Nutritional status at baseline } \\
\hline Normal & $1 \cdot 00$ & & & $1 \cdot 00$ & & \\
\hline Underweight & $1 \cdot 18$ & $(0 \cdot 81-1 \cdot 72)$ & $0 \cdot 399$ & $1 \cdot 16$ & $(0 \cdot 78-1 \cdot 69)$ & $0 \cdot 433$ \\
\hline Overweight & 0.67 & $(0 \cdot 45-1 \cdot 01)$ & $0 \cdot 054$ & $0 \cdot 64$ & $(0 \cdot 43-0 \cdot 95)$ & $0 \cdot 029$ \\
\hline \multicolumn{7}{|l|}{ Treatment for $\mathrm{TB}$ during the cohort } \\
\hline No & $1 \cdot 00$ & & & $1 \cdot 00$ & & \\
\hline Yes & $3 \cdot 85$ & $(2 \cdot 80-5 \cdot 29)$ & $0 \cdot 000$ & $4 \cdot 01$ & $(2 \cdot 95-5 \cdot 44)$ & $0 \cdot 000$ \\
\hline \multicolumn{7}{|l|}{ Chemoprophylaxis for $\mathrm{TB}$ during the cohort } \\
\hline Not indicated and not treated for LTBI & $1 \cdot 00$ & & & & & \\
\hline Indicated and treated for LTBI & 0.95 & $(0 \cdot 38-2 \cdot 40)$ & $0 \cdot 922$ & & & \\
\hline Indicated and not treated for LTBI & $0 \cdot 89$ & $(0 \cdot 47-1 \cdot 69)$ & $0 \cdot 729$ & & & \\
\hline No tuberculin skin test & 0.97 & $(0 \cdot 70-1 \cdot 35)$ & $0 \cdot 849$ & & & \\
\hline
\end{tabular}

PLWH, People living with HIV/AIDS; SHR, sub-distribution hazard ratio; CI, confidence interval; LTBI, latent tuberculosis infection.

Mean values in dollars for Brazilian minimum salary: US\$185.64 (2007); US\$246.88 (2008); US\$198.13 (2009); US\$295.82 (2010); US\$327.92 (2011); US\$332.98 (2012); 
Table 5. Sensitivity analysis: multivariate regression model of the sub-distribution hazards of immunodeficiency-related death, considering other deaths as competing event, in a subsample of 373 PLWH with available CD4 counts, 2007-2012

\begin{tabular}{|c|c|c|c|}
\hline Predictor variables & $\begin{array}{l}\text { Adjusted } \\
\text { SHR }\end{array}$ & $95 \% \mathrm{CI}$ & $P$ value \\
\hline \multicolumn{4}{|c|}{ Treatment for $\mathrm{TB}$ during the cohort } \\
\hline No & $1 \cdot 00$ & & \\
\hline Yes & $4 \cdot 55$ & $(3 \cdot 15-6 \cdot 58)$ & $0 \cdot 000$ \\
\hline \multicolumn{4}{|l|}{ Anaemia at baseline } \\
\hline No & $1 \cdot 00$ & & \\
\hline Yes & $3 \cdot 23$ & $(2 \cdot 14-4 \cdot 87)$ & $0 \cdot 000$ \\
\hline Not informed & $5 \cdot 51$ & $(3 \cdot 04-9 \cdot 97)$ & $0 \cdot 000$ \\
\hline \multicolumn{4}{|c|}{ CD4 cell count at baseline } \\
\hline$\geqslant 200$ cells $/ \mathrm{mm}^{3}$ & $1 \cdot 00$ & & \\
\hline $1-199$ cells $/ \mathrm{mm}^{3}$ & $3 \cdot 82$ & $(2 \cdot 70-5 \cdot 43)$ & $0 \cdot 000$ \\
\hline \multicolumn{4}{|l|}{ Nutritional status } \\
\hline Normal & $1 \cdot 00$ & & \\
\hline Underweight & $0 \cdot 95$ & $(0 \cdot 58-1 \cdot 56)$ & $0 \cdot 840$ \\
\hline Overweight/obese & $0 \cdot 57$ & $(0 \cdot 35-0 \cdot 91)$ & $0 \cdot 020$ \\
\hline
\end{tabular}

PLWH, People living with HIV/AIDS; SHR, sub-distribution hazard ratio; CI, confidence interval.

Thus, it is extremely important to investigate TB as an independent risk factor for deaths in PLWH in our endemic area [2]. In our study, TB/HIV co-infection differentiated a group with a fourfold risk of death from immunodeficiency, in agreement with a Cambodian study [29]. Moreover, TB is associated with severe anaemia which is a strong predictor of both TB and death in PLWH [33]. Anaemia is associated to a substantial reduction in the survival of PLWH [34-36], irrespective of co-infections and levels of CD4 cells [10, 34]. Severe anaemia may increase mortality by several times, such as a rate of 15 times, as observed in an African study [37]. Our study adds that the presence of anaemia at the beginning of the follow-up increases the cause-specific risk of dying from HIV immunodeficiency by three times.

During the HAART era, factors related to lifestyle, such as alcohol intake, reduce the long-term survival of PLWH [13]. On the other hand, light or moderate alcohol intake [38], as well as employment [39], may be associated to longer survival rates in PLWH. More specifically, some cohort studies have reported a twofold risk of AIDS-related deaths in patients who were unemployed [40]. Employment may indicate differences in accessing healthcare and its quality [39]. Accordingly, in our study the risk of dying from HIV immunodeficiency was one-third lower in light drinkers and workers compared to non-drinkers and non-workers. We would expect that underweight patients [10], not taking HAART [26] and those who were most vulnerable to TB (positive TST without treatment for LTBI) [29] would present a greater risk of immunodeficiency-related death. However, our analyses have not encountered such an association. Possibly this study did not have the statistical power to detect these issues.

The differences between the groups of immunodeficiency-related and -unrelated deaths regarding CD4 count $<200$ cells $/ \mathrm{mm}^{3}(40 \%$ vs. $10 \%)$ and anaemia $(60 \%$ vs. $40 \%)$, reinforced the hazards ratios of these predictors for immunodeficiency-related death. However, in the patients who died from immunodeficiency, no CD4 data was available for almost $40 \%$, and no $\mathrm{Hb}$ data for $20 \%$, while TST was only available for less than half of the patients. These missing data may hinder observing the actual differences in the hazards. In the subsample of patients with available CD4 counts, non-workers and light drinkers lost their effect, showing that these socioeconomic variables are sensitive to the availability of laboratory tests. This finding might be explained by an interrelation between socioeconomic condition, the severity of HIV infection and access to healthcare facilities. Accordingly, patients not having CD4 or $\mathrm{Hb}$ data had higher SHR than those with low CD4 cell count or anaemia.

We created the 'not informed' categories to avoid a selection bias from exclusion of missing data. However, in patients without CD4 results a misclassification on the cause of death may have occurred. Nevertheless, $70 \%$ of deaths could be attributed to HIV immunodeficiency. On the other hand, we addressed the overestimation on immunodeficiency caused by the ICD-10 system [14] using the CoDe Review Form. Furthermore, we applied Fine \& Gray's method to address the bias from competing risks [15]. Therefore, we believe that our analyses brought a more reliable understanding regarding HIV lethality in northeast Brazil, and corroborated that the introduction of HAART with free access in the public health services does not seem to have assured a wide coverage by HAART nor did it reduce mortality trends in PLWH in our region as in other regions of Brazil $[6,7,17]$ and in other countries $[2,12]$.

\section{CONCLUSIONS}

Even in the HAART era, $75 \%$ of PLWH who died in our region did so due to immunodeficiency, where the 
leading cause was TB. Anaemia at baseline or incidence of TB increase the specific risk of dying from immunodeficiency by several times. We recommend a careful management of anaemia and TB as important HIV comorbidities, and efforts to investigate the reasons that have limited the effectiveness of HAART on the survival estimates of PLWH in our region. We encourage researchers to use the CoDe and competing risks methods in studies regarding mortality in PLWH worldwide.

\section{ACKNOWLEDGEMENTS}

This study received support from the Ministério da Saúde/Programa DST/AIDS/UNESCO (CSV 182/06 Project Estudo Clínico-Epidemiológico da Co-infecção HIV/Tuberculose em Recife); the authors received partial support from the Conselho Nacional de Desenvolvimento Científico e Tecnológico-CNPq (scholarship to J.D.L.B., grant no. 150425/2012-0; and to M.F.P.M.A., grant no. 308 491/2013-0).

\section{DECLARATION OF INTEREST}

None.

\section{REFERENCES}

1. von Braun A, et al. Antiretroviral therapy [in German]. Therapeutische Umschau 2014; 71: 461-468.

2. Smith CJ, et al. Trends over time in underlying causes of death amongst HIV-positive individuals from 1999 to 2011. Lancet 2014; 384: 241-248.

3. Marin B, et al. Non-AIDS-defining deaths and immunodeficiency in the era of combination antiretroviral therapy. AIDS 2009; 23: 1743-1753.

4. Kowalska JD, et al. The Coding Causes of Death in HIV (CoDe) Project: initial results and evaluation of methodology. Epidemiology; 22. Published online: July 2011. doi:10.1097/EDE.0b013e31821b5332.

5. Weber R, et al. Decreasing mortality and changing patterns of causes of death in the Swiss HIV Cohort Study. HIV Medicine 2013; 14: 195-207.

6. Pacheco AG, et al. Temporal changes in causes of death among HIV-infected patients in the HAART era in Rio de Janeiro, Brazil. Journal of Acquired Immune Deficiency Syndromes 2009; 51: 624-630.

7. Grinsztejn B, et al. Changing mortality profile among HIV-infected patients in Rio de Janeiro, Brazil: shifting from AIDS to non-AIDS related conditions in the HAART era. PLOS ONE 2013; 8: 59-68.

8. GBD 2015 HIV Collaborators. Estimates of global, regional, and national incidence, prevalence, and mortality of HIV, 1980-2015: The Global Burden of Disease Study 2015. Lancet HIV 2016; 3: e361-e387.
9. Girardi E, et al. Impact of previous ART and of ART initiation on outcome of HIV-associated tuberculosis. Clinical and Developmental Immunology. Published online: 12 January 2012. doi:10.1155/2012/931325.

10. Tadesse K, Haile F, Hiruy N. Predictors of mortality among patients enrolled on antiretroviral therapy in Aksum Hospital, Northern Ethiopia: a retrospective cohort study. PLoS ONE. Published online: 31 January 2014. doi: 10.1371/journal.pone.0087392.

11. Floyd S, et al. The effect of antiretroviral therapy provision on all-cause, AIDS and non-AIDS mortality at the population level - a comparative analysis of data from four settings in Southern and East Africa. Tropical Medicine and International Health 2012; 17: e84-e93.

12. Helleberg M, et al. Mortality attributable to smoking among HIV-1-infected individuals: a nationwide, population-based cohort study. Clinical Infectious Diseases 2013; 56: 727-734.

13. Obel N, et al. Impact of non-HIV and HIV risk factors on survival in HIV-infected patients on HAART: a population-based nationwide cohort study. PLoS ONE. Published online: 25 July 2011. doi: 10.1371/journal.pone.0022698.

14. Hernando V, et al. Differences in the causes of death of HIV-positive patients in a cohort study by data sources and coding algorithms. AIDS 2012; 26: 1829-1834.

15. Pintilie M. An introduction to competing risks analysis. Revista Española de Cardiología 2011; 64: 599-605.

16. Brazilian Ministry of Health. HIV/AIDS Epidemiological Bulletin, Brasília, Brazil: Centre of Health Surveillance/Department of STD, AIDS and Viral Hepatitis, 2015.

17. Batista DA. The impact of antiretroviral therapy in years of life lost and cause of death by AIDS in Pernambuco - 1990 to 2005 (dissertation). Recife, PE, Brazil: Aggeu Magalhães Research Center, Oswaldo Cruz Foundation, 2010, 100 pp.

18. Batista JDL, et al. Incidence and risk factors for tuberculosis in People living with HIV: Cohort from HIV referral health centers in Recife, Brazil. PLoS ONE. Published online: 10 May 2013. doi: 10.1371/journal. pone.0063916.

19. Fine JP, Gray RJ. A proportional hazards model for the subdistribution of a competing risk. Journal of the American Statistical Association 1999; 94: 496-509.

20. Camargo KR Jr., Coeli CM. Reclink: an application for database linkage implementing the probabilistic record linkage method. Cadernos de Saúde Pública 2000; 16: 439-447.

21. Centers for Disease Control and Prevention (CDC). Alcohol and Public Health: Fact Sheets-Alcohol (http://www.cdc.gov/alcohol/fact-sheets.htm). Accessed 25 April 2016.

22. World Health Organization (WHO). Diet, nutrition and the prevention of chronic diseases. Report of a WHO Study Group Geneva, 1990; WHO Technical Report Series (TRS) 90-797; no. 797.

23. Mocroft A, et al. Anaemia is an independent predictive marker for clinical prognosis in HIV-infected patients from across Europe. AIDS 1999; 13: 943-950. 
24. Brazilian Ministry of Health. Manual of recommendations for the control of tuberculosis in Brazil, Brasília, Brazil: Centre of Health Surveillance/Department of Epidemiological Surveillance, 2011, Series and Technical Manuals, series A.

25. Golub JE, et al. Isoniazid preventive therapy, HAART and tuberculosis risk in HIV infected adults in South Africa: a prospective cohort. AIDS 2009; 23: 631-636.

26. The Antiretroviral Therapy Cohort Collaboration. Causes of death in HIV-1-infected patients treated with antiretroviral therapy, 1996-2006: collaborative analysis of 13 HIV cohort studies. Clinical Infectious Diseases 2010; 50: 1387-1396.

27. Kowalska JD, et al. Long-term exposure to combination antiretroviral therapy and risk of death from specific causes: no evidence for any previously unidentified increased risk due to antiretroviral therapy. AIDS 2012; 26: 315-323.

28. Geldmacher $\mathbf{C}$, et al. Preferential infection and depletion of Mycobacterium tuberculosis-specific CD4 T cells after HIV-1 infection. Journal of Experimental Medicine 2010; 207: 2869-2881.

29. Marcy O, et al. Causes and determinants of mortality in HIV infected adults with tuberculosis: an analysis from the CAMELIA ANRS 1295-CIPRA KH001 randomized trial. Clinical Infectious Diseases 2014; 59: 435445.

30. Diedrich CR, Flynn JL. HIV-1/mycobacterium tuberculosis coinfection immunology: how does HIV-1 exacerbate tuberculosis? Infection and Immunity 2011; 79: 1407-1417.

31. Saraceni V, et al. Tuberculosis as primary cause of death among AIDS cases in Rio de Janeiro, Brazil. The International Journal of Tuberculosis and Lung Disease 2008; 12: 769-772.

32. Vijay S, et al. Treatment outcome and mortality at one and half year follow-up of HIV infected TB patients under TB Control Programme in a district of South
India. PLoS ONE. Published online: 26 July 2011. doi: 10.1371/journal.pone.0021008.

33. Kerkhoff AD, et al. The predictive value of current haemoglobin levels for incident tuberculosis and/or mortality during long-term antiretroviral therapy in South Africa: a cohort study. BMC Medicine 2015; 13: 70 .

34. Sullivan PS, et al. Epidemiology of anemia in human immunodeficiency virus (HIV)-infected persons: results from the multistate adult and adolescent spectrum of HIV disease surveillance project. Blood 2014; 91: 301-308.

35. Tuboi SH, et al. Mortality during the first year of potent antiretroviral therapy in HIV-1-infected patients in 7 sites throughout Latin America and the Caribbean. Journal of Acquired Immune Deficiency Syndromes 2009; 51: 615-623.

36. Sieleunou I, et al. Determinants of survival in AIDS patients on antiretroviral therapy in a rural centre in the Far-North Province, Cameroon. Tropical Medicine and International Health 2009; 14: 36-43.

37. Johannessen A, et al. Predictors of mortality in HIVinfected patients starting antiretroviral therapy in a rural hospital in Tanzania. BMC Infectious Diseases 2008; 8: 52.

38. Wandeler G, et al. The J-curve in HIV: better cardiovascular disease free survival with moderate alcohol intake. Journal of Acquired Immune Deficiency Syndromes 2015; 71: 302-309.

39. Tjepkema M, Wilkins R, Long A. Cause-specific mortality by occupational skill level in Canada: a 16-year follow-up study. Chronic Diseases and Injuries in Canada 2013; 33: 195-203.

40. Wada N, et al. Cause-specific life expectancies after 35 years of age for human immunodeficiency syndromeinfected and human immunodeficiency syndrome-negative individuals followed simultaneously in long-term cohort studies, 1984-2008. American Journal of Epidemiology 2013; 177: 116-125. 